\title{
Photosynthesis of leaves and field crop'
}

\section{P. GAASTRA}

National Council for Agricultural Research; Laboratory of Plant Physiological

Research, Agricultural University, Wageningen, Netherlands

\section{Summary}

Photosynthesis of leaves is analysed in terms of limiting processes. The capacities of the photochemical and diffusion processes limit photosynthesis simultaneously for a wide range of light intensities and temperatures. The intrinsic properties of the photochemical process are rather constant, so that the rate of this process can be influenced primarily by variation of the light intensity. The diffusion rate depends both on the magnitude of various diffusion resistances and on the external $\mathrm{CO}_{2}$-concentration.

Daily photosynthesis per soil-area unit of field crops is influenced by various physiological and structural properties of the crop. In this connection, the size of the diffusion resistances, spatial arrangement of the leaves, and leaf area per unit of soil area, are important rate-determining factors. Furthermore, photosynthesis of field crops is determined by several meteorological features, e.g. turbulence of the air, and diurnal courses of solar radiation and of solar elevation.

\section{Introduction}

It is the aim of most types of agriculture to obtain high yields of good quality of those plant organs which are of economical interest. These yields, therefore, depend on the total dry matter present at harvest and on the dry-matter distribution over the organs of the plant. Most certainly, the optimum distribution of daily produced dry matter varies during the ontogeny of the plants. For analysing the productivity of field crops one should like to be informed on actual and optimum daily drymatter productions per unit of soil area and on the actual and optimum patterns of dry-matter distribution during the development of the crop. In this paper some aspects of the dry-matter production by field crops will be considered.

Almost all dry matter present in higher plants originates from photosynthetic $\mathrm{CO}_{2}-$ reduction:

$$
\mathrm{CO}_{2}+\mathrm{H}_{2} \mathrm{O}+\text { light } \longrightarrow\left(\mathrm{CH}_{2} \mathrm{O}\right)+\mathrm{O}_{2}-112000 \mathrm{cal}
$$

In growing plants, however, energy is needed for several other processes, e.g. for the formation of various plant constituents and for the active uptake or transport of water, minerals and assimilates. Most of this energy is supplied by respiratory processes in which carbohydrates formed earlier or elsewhere in the plant are used as a substrate:

$$
\left(\mathrm{CH}_{2} \mathrm{O}\right)+\mathrm{O}_{2} \longrightarrow \mathrm{CO}_{2}+\mathrm{H}_{2} \mathrm{O}+112000 \mathrm{cal}
$$

1 Lecture held at the course "Fundamentals of dry-matter production and distribution" organized by the Royal Netherlands Society for Agricultural Sciences, Wageningen, 9th January, 1962. 
Net photosynthesis $\left(P_{n}\right)$ is the difference between gross photosynthesis $\left(P_{g}\right)$ and respiration $(R)$ :

$$
\mathbf{P}_{\mathrm{n}}=\mathbf{P}_{\mathrm{g}}-\mathbf{R}
$$

The respiration rate per plant and per day can be as high as 25 to $50 \%$ of the daily gross photosynthesis so that for analytical purposes $P_{g}$ and $R$ should be known. In most experimental techniques $P_{n}$ is measured directly. Usually, it is assumed that the relation between temperature and respiration is similar in light and in dark, so that the value of $R$ in the light period - and, consequently, that of $P_{g}-$ can be derived from actually observed respiration rates in darkness.

Photosynthesis of crop surfaces usually shows a pronounced diurnal course as a result of the variation in solar radiation during the day. Therefore, the diurnal courses of $P_{g}$ and $R$ should preferably be considered when an analysis of the production of field crops is attempted. In this paper some properties of leaves of crop plants are discussed which could facilitate the interpretation of the daily photosynthetic activity of crop surfaces.

\section{Processes limiting photosynthesis of leaves}

The photosynthetic process consists of several processes and for the present purpose the following three types can be distinguished:

a. A diffusion process for the transport of $\mathrm{CO}_{2}$ from the external air towards the chloroplasts. The rate of this process depends mainly on the $\mathrm{CO}_{2}$-concentration in the external air and only slightly on temperature. Light can affect the diffusion rate only indirectly through an influence on the stomatal diffusion resistance.

b. A photochemical process which results in the conversion of light energy into "assimilatory power" which is used for the reduction of $\mathrm{CO}_{2}$. The photochemical process is influenced by light and not by $\mathrm{CO}_{2}$ or temperature.

c. Biochemical processes which precede and succede the reduction of $\mathrm{CO}_{2}$ finally result in the formation of carbohydrates. The biochemical processes are strongly affected by temperature and not by light. In most cases $\mathrm{CO}_{2}$ has little or no effect.

The partial processes are affected in a different way by external conditions so that, according to the well-known concept of limiting factors, the processes limiting photosynthesis can be identified by studying the effects of independently varied light intensity, $\mathrm{CO}_{2}$-concentration, and temperature upon the rate of photosynthesis. Such experiments have been done with leaves of various crop plants and, as an example, results obtained with leaves of cucumber are presented in FIG. 1.

At low light intensities (between dark and about $10^{4} \mathrm{erg} . \mathrm{sec}^{-1} . \mathrm{cm}^{-2}$ ) the relation between photosynthesis and light intensity is linear, which indicates that the photochemical process is limiting. With a further increase in light intensity, photosynthesis increases less rapidly until finally (at about $10 \times 10^{4} \mathrm{erg} . \mathrm{sec}^{-1} . \mathrm{cm}^{-2}$ in air with normal $\mathrm{CO}_{2}$-concentration (about $0,03 \% \mathrm{CO}_{2}$ )) complete light saturation is reached. At saturating light intensities and in normal air, photosynthesis is strongly affected by variations in $\mathrm{CO}_{2}$-concentration (cf. FIG. 1) but only slightly by temperature in the range between about $15^{\circ}$ and $30^{\circ} \mathrm{C}$. Therefore, the capacity of the diffusion process is limiting under these conditions. 


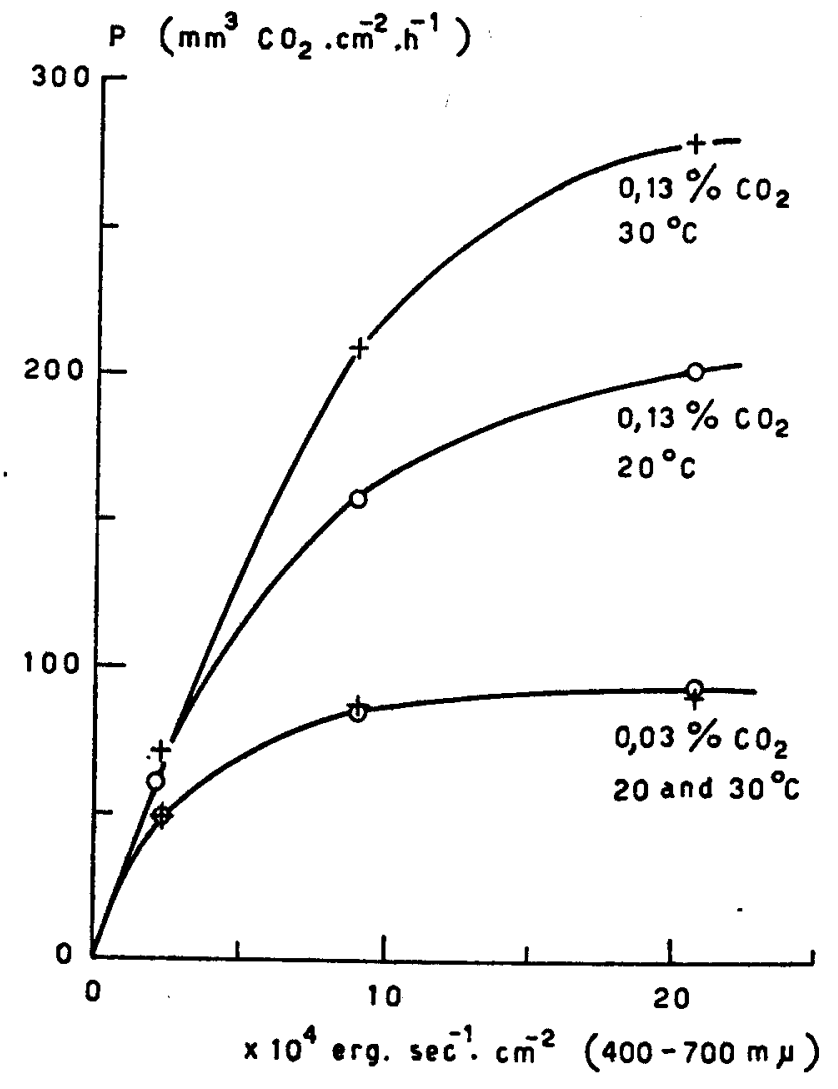

Fig. 1

Photosynthesis (P) of a cucumber leaf in relation to light intensity and temperature at a limiting $(0,03 \%)$ and at a saturating $(0,13 \%)$ $\mathrm{CO}_{2}$-concentration. Light source: incandescent lamp $500 \mathrm{~W}$ (unpublished experiments by the author)

Photosynthesis at saturating $\mathrm{CO}_{2}$-concentrations $\left(0,13 \% \mathrm{CO}_{2}\right.$ in FIG. 1) and light intensities is influenced by variation of temperature. This indicates that the photosynthetic rate is determined by the capacity of a biochemical process under these conditions.

For leaves well supplied with water, the maximum rate of photosynthesis in normal air is about $100-150 \mathrm{~mm}^{3} \mathrm{CO}_{2} \cdot \mathrm{cm}^{-2} \cdot \mathrm{h}^{-1}$. Usually, the photosynthetic rate at saturating light intensities and $\mathrm{CO}_{2}$-concentrations (i.e. the capacity of the biochemical processes) and at $20^{\circ}-25^{\circ} \mathrm{C}$ is about 2 or 3 times as high as the maximum rate in normal air. When the leaves are well supplied with water, $\mathrm{CO}_{2}$-saturation is reached in air containing about $0,1-0,15 \% \mathrm{CO}_{2}$ (Hoover et al., 1933; GAASTRA, 1959).

The shape of the curve which relates photosynthesis per leaf-area unit to light intensity, deviates appreciably from the ideal Blackman-curve. Fig. 1 illustrates that there is a wide range of light intensities (between about $10^{4}$ and $10^{5} \mathrm{erg} . \mathrm{sec}^{-1} . \mathrm{cm}^{-2}$ ) at which photosynthesis in normal air is influenced by variations in light intensity and also by variations in $\mathrm{CO}_{2}$-concentration. Apparently, the capacities of the photochemical and diffusion processes limit photosynthesis simultaneously at these transitional light intensities. Probably, the wide transition range is caused by uneven illumination of the various chloroplasts in the leaves. About $10 \%$ of the incident visible radiation is reflected and a similar amount is transmitted by most leaves of crop 
plants (Seybold and Werssweiler, 1942, 1943; Rabideau et al., 1946; Moss and Loomis, 1952). The light intensity at the exposed side of the leaf is, therefore, about 9 times as high as the intensity at the opposite side. As a consequence, the chloroplasts near the irradiated leaf side reach light saturation at lower light intensities (at the exposed leaf surface) then those near the opposite side. Therefore, the relation between photosynthesis per unit of leaf area and incident light deviates from linearity as soon as the most exposed chloroplasts become saturated with light, and light saturation of the whole leaf is complete when the most shaded chloroplasts reach light saturation.

The data for the cucumber leaf represent the behaviour of leaves of various crop plants fairly well, so that it can be concluded that for a wide range of ecologically interesting conditions, photosynthesis of leaves is determined by the capacities of the photochemical and/or diffusion process. Consequently, photosynthesis under natural conditions can be affected directly by variations of light intensity and CO-concentration. Temperature, on the other hand, has a slight effect only in a rather large range of temperatures between about $15^{\circ}$ and $30^{\circ} \mathrm{C}$.

\section{The capacity of the photochemical process in leaves}

At low, completely limiting light intensities the photosynthetic rate is determined by the capacity of the photochemical process. The capacity of this partial process is, therefore, represented by the efficiency of light utilization at these light intensities. Fundamentally, the efficiency of light utilization is best expressed by the quantum yield, $\Phi$ :

$$
\Phi=\frac{\text { moles } \mathrm{CO}_{2} \text { converted }}{\text { quanta absorbed }}
$$

or by the quantum requirement, $\Phi^{-1}$.

To obtain the number of quanta absorbed, the light absorption by the leaf and the energy emission of the light source, both as a function of wave length, should be known. In most investigations of the photosynthetic activity of leaves, these features are not measured. With suitable radiation meters and light filters, however, the incident light in the region $400-700 \mathrm{~m} \mu$ can be measured rather easily (cf. GaAsTRA, 1959) so that the photochemical process is usually characterized by the efficiency of light energy conversion, $\varepsilon$ :

$$
\varepsilon=\frac{\text { calories }\left(\mathrm{CH}_{2} \mathrm{O}\right) \text { formed } \times 100}{\text { calories incident light }(400-700 \mathrm{~m} \mu)}
$$

At first sight, $\varepsilon$ seems to be a rather indirect measure of the properties of the photochemical process, because it can be influenced by the absorption characteristics of the leaf and by the effect of wave length on the energy content per quantum. In many cases, however, the ratio $\Phi / \varepsilon$ is rather constant for leaves with different chlorophyll concentrations and for leaves exposed to different light sources: for most "white" light sources the number of quanta absorbed per unit of incident light energy $(400-700 \mathrm{~m} u)$ is rather similar for leaves with average absorption characteristics (GAASTRA, 1959), and the maximum value of $\varepsilon$ is only slightly affected by 
the chlorophyll concentration per leaf-area unit in a range of frequently occurring concentrations, cf. FIG. 2 (GABRIELSEN, 1948).

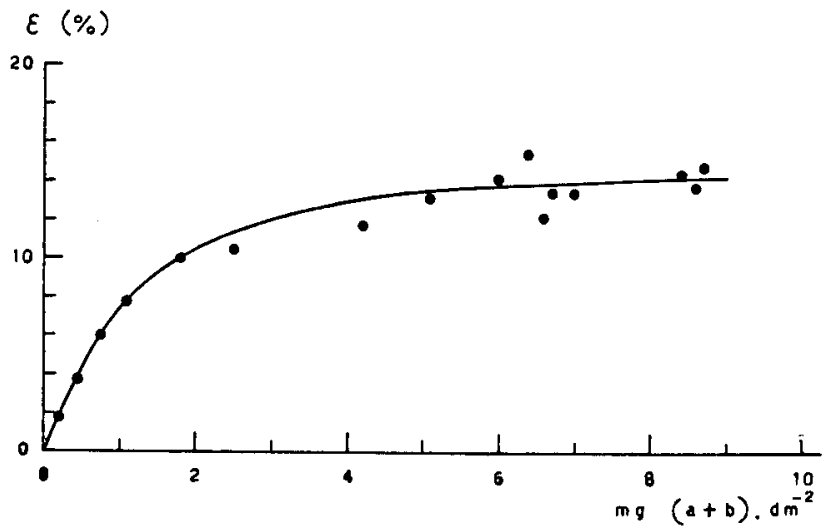

FIg. 2

Maximum efficiency of light energy conversion $(\varepsilon)$ in relation to chlorophyll concentration per unit leaf area. Leaves of different species. Light source: Osram-nitra lamp $1500 \mathrm{~W}$ (from GABRIELSEN, 1948)

Gabrielsen's data are in agreement with Boysen Jensen's (1932) observation (cf. also TALling, 1961) that the maximum efficiency of light utilization at low light intensities is about the same for leaves of different species and for leaves grown under different environmental conditions. This is also illustrated in FIG. 3 where photosynthesis per unit of leaf area is plotted against light intensity for leaves of different species (unpublished experiments carried out by the author at Rothamsted Experimental Station, Harpenden). All plants were grown in containers filled with soil. The wheat, barley and field-bean plants were 4 to 8 weeks old and were well supplied with water. The grass and kale plants were older and for these plants the water supply was probably sub-optimal. For all leaves, however, photosynthesis at low light intensities was of the same order of magnitude and appreciable differences

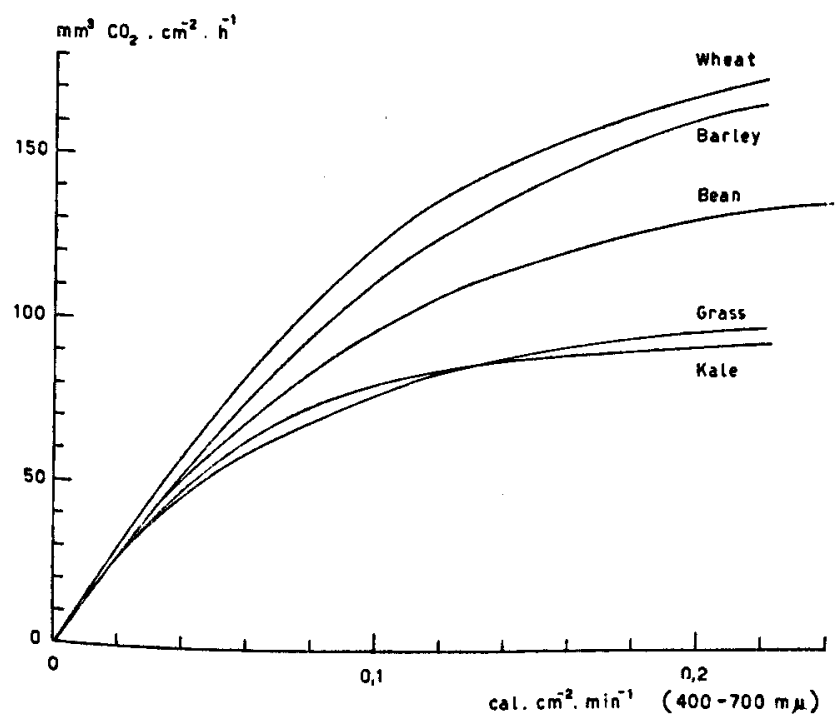

Frg. 3

Photosynthesis of leaves of various crop plants in relation to light intensity. Light source: MBFR/U - $400 \mathrm{~W}$, Philips; $21-25^{\circ} \mathrm{C} ; 0,030$ $0,032 \% \quad \mathrm{CO}_{2}$ (unpublished experiments by the author) 
occurred at high light intensities only. This indicates that the properties of the photochemical process were very similar, whereas the capacities of the diffusion process differed widely.

For the leaves in FIG. 3, the maximum efficiency of light-energy conversion was about $12,5 \%$. For the light source used and for leaves with average absorption characteristics, this corresponds with a quantum requirement $\Phi^{-1}=12$ (GAastra, 1962). This value is close to the minimum requirements $(10-12)$ observed for leaves of crop plants ( $c f$. Wassink, 1946; Gabrielsen, 1947; GaAstra, 1959).

These data suggest, therefore, that the properties of the photochemical process in different leaves are rather similar, and that the actual capacities are close to the optimum capacities of this process. Consequently, the rate of the photochemical process can be influenced primarily by variation of the light intensity and much less by variation of the intrinsic properties of the process.

\section{The capacity of the diffusion process in leaves}

During the transport of $\mathrm{CO}_{2}$ from the external air towards the reaction centre in the chloroplasts, several diffusion resistances are encountered. The most important resistances are located in the external air near the leaf surface $\left(r_{a}\right)$, in the stomata $\left(r_{s}\right)$, and in the mesophyll cells $\left(r_{m}\right)$, cf. GaAsTra $(1959,1962)$. Under steadystate conditions, the rate of photosynthesis (P) equals the diffusion rate, which is expressed by

$$
P=\frac{c_{a}-c_{c b l}}{r_{2}+r_{s}+r_{m}}
$$

in which $c_{2}$ and $c_{c b l}$ are $\mathrm{CO}_{2}$-concentrations $\left(\mathrm{cm}^{3} \mathrm{CO}_{2} . \mathrm{cm}^{-3}\right)$ in the external air and near the chloroplasts, respectively; $\mathrm{P}$ is expressed in $\mathrm{cm}^{3} \mathrm{CO}_{2} . \mathrm{cm}^{-2}$ leaf. $\mathrm{sec}^{-1}$, and the resistances in $\mathrm{sec} . \mathrm{cm}^{-1} . \mathrm{cm}^{-2}$ leaf.

When the capacity of the diffusion process is limiting photosynthesis, $c_{c h l}$ is close to zero and in that case

$$
P=\frac{c_{z}}{\sum r}
$$

It was shown in FIG. 3 that the photosynthetic rates of various leaves can be different at saturating light intensities. Since the value of $c_{a}$ was of similar magnitude (about $0,03 \% \mathrm{CO}_{2}$ ), the differences must be caused by different values of the total diffusion resistance, $\Sigma \mathrm{r}$. In contrast to the photochemical process, therefore, the capacity of the diffusion process can be appreciably influenced by variation of the intrinsic properties of the process. Of course, at limiting $\mathrm{CO}_{2}$-concentrations the diffusion rate is also affected by variation of $c_{a}$, as illustrated in FIG. 1 .

For a wide range of outside conditions, the photosynthetic rate of leaves is determined by the capacities of the photochemical and/or diffusion process (cf. section 2 ). Consequently the potential possibilities to increase the rate of photosynthesis depend primarily on the difference between the potential and actual capacities of these partial processes. For the diffusion process of the cucumber leaf in FIG. 1, these possibilities are represented by the ratio of the photosynthetic rates at saturating and at normal $\mathrm{CO}_{2}$-concentrations. This ratio, $\mathrm{P}_{0,13} / \mathrm{P}_{0,03}$, is plotted against light intensity 
in FIG. 4. The highest value is 2,2 and the maximum is not yet reached at the highest light intensity applied. It is also shown that photosynthesis in the transition range (between $10^{4}$ and $10^{5} \mathrm{erg} \cdot \mathrm{sec}^{-1} \cdot \mathrm{cm}^{-2}$ ) and in normal air can be appreciably affected by an increased capacity of the diffusion process (cf. also curves in Hoover et al., 1933; ChapMan and Loomis, 1953; GaAstra, 1959).

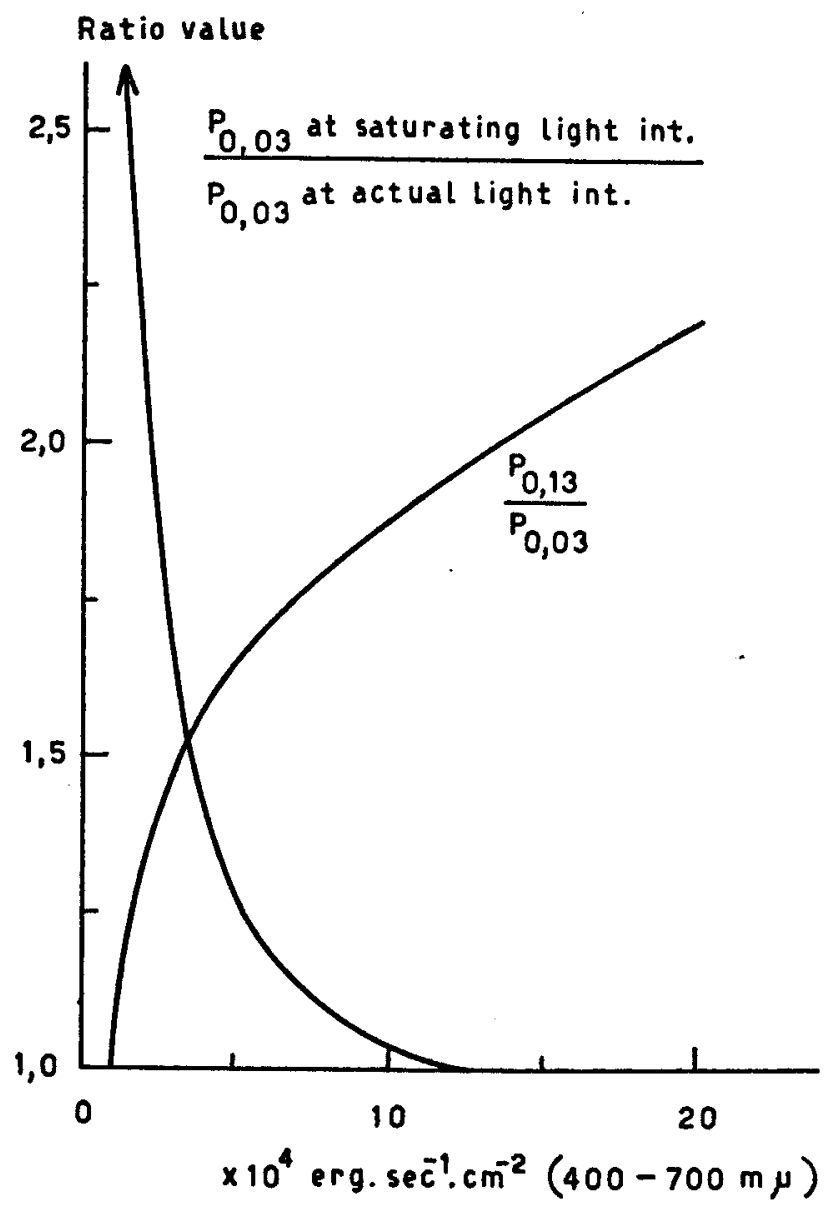

Fro. 4

Maximum effects of increased light intensity or decreased diffusion resistance on photosynthesis in normal air and at $20^{\circ} \mathrm{C}$ for the cucumber leaf presented in FIG. 1 (for explanation see text)

It was mentioned earlier that the intrinsic properties of the photochemical process are rather constant. Therefore, the most effective way of increasing the rate of the photochemical process is obtained by exposure of the leaves to favourable light intensities. With leaves in normal air the maximum effect is expressed by the ratio between the photosynthetic rates at saturating and at actual light intensities. This ratio is also plotted in FIG. 4 and comparison with the ratio $\mathrm{P}_{0,13} / \mathrm{P}_{0,03}$ shows that for light intensities from $4 \times 10^{4} \mathrm{erg} \cdot \mathrm{sec}^{-1} . \mathrm{cm}^{-2}$ upwards, photosynthesis in normal air could, potentially, be increased more by increasing the rate of the diffusion process than by increasing the rate of the photochemical process.

The maximum rates of photosynthesis observed in normal air and at saturating light intensities, are between 100 and $150 \mathrm{~mm}^{3} \mathrm{CO}_{2} \cdot \mathrm{cm}^{-2} \cdot \mathrm{h}^{-1}$. Under these conditions, 
the capacity of the diffusion process limits photosynthesis and according to eq. (7) the total diffusion resistance then is between 10 and $7 \mathrm{sec} . \mathrm{cm}^{-1} \cdot \mathrm{cm}^{-2}$ leaf. For analytical purposes, the values of the separate resistances should also be known because variation of a single resistance affects the diffusion rate through an effect upon the total resistance.

The external air resistance of a single leaf $\left(r_{a}\right)$ is affected by size and shape of the leaf, nature of the leaf surface, and wind velocity. For an average leaf, $r_{a}$ is about 3,$3 ; 1,7 ; 0,9$ and $0,4 \mathrm{sec} . \mathrm{cm}^{-1} \cdot \mathrm{cm}^{-2}$ leaf for wind velocities of $16 ; 42 ; 100$ and $300 \mathrm{~cm} \cdot \mathrm{sec}^{-1}$ respectively (cf. GaAstra, 1962). Since the total diffusion resistance is about $10 \mathrm{sec} . \mathrm{cm}^{-1}$, variation of the wind velocity can affect photosynthesis at low wind speeds only.

Only few data are available on absolute values of $r_{s}$, because no simple relationship exists between $r_{s}$ and most features actually measured (infiltration rates, length or width of stomatal slit, porometer rate, etc.). For leaves well supplied with water, $r_{s}$ can be derived from simultaneously measured rates of transpiration and leaf temperature, cf. Bange (1953), GaAstra (1959), Kuiper (1961). Minimum values of $r_{s}$ obtained in this way (see the TABLE) are much smaller than the minimum resistance of the total diffusion path. Similarly, the diffusion rates to be expected if the difference between the $\mathrm{CO}_{2}$-concentrations at both ends of the stomatal pores could be maintained at $0,03 \% \mathrm{CO}_{2}\left(\mathrm{P}_{s}\right.$ in the TABLE), are much larger than the rates of photosynthesis actually observed in normal air.

Stomatal diffusion resistance $\left(r_{s}\right.$ in $\sec . \mathrm{cm}^{-1} \cdot \mathrm{cm}^{-2}$ leaf $)$ and rate of $\mathrm{CO}_{2}$-diffusion when the difference between the $\mathrm{CO}_{2}$-concentrations at both ends of the stomatal pores is $0,03 \% \mathrm{CO}_{2}\left(\mathrm{P}_{\mathrm{s}}\right.$ in $\left.\mathrm{mm}^{3} \mathrm{CO}_{2} \cdot \mathrm{cm}^{-2} \cdot \mathrm{h}^{-1}\right)$

\begin{tabular}{|c|c|c|c|}
\hline Species & $\mathbf{r}_{\mathrm{s}}$ & $\mathbf{P}_{\mathrm{s}}$ & Author \\
\hline Zebrina & 1,5 & 701 & Bange (1953) \\
\hline $\begin{array}{l}\text { turnip } \ldots \ldots \ldots \ldots \\
\text { sugar beet } \ldots \ldots \ldots\end{array}$ & $2,7-3,1$ & $400-350$ & Gaastra (1959) \\
\hline $\begin{array}{l}\text { bean } \ldots \ldots \ldots \ldots \ldots \\
\text { tomato } \ldots \ldots \ldots \ldots \\
\text { Hyoscyamus } \ldots \ldots\end{array}$ & $4,1-5,8$ & $263-186$ & Kuiper (1961) \\
\hline
\end{tabular}

These data indicate already that the mesophyll resistance $\left(r_{m}\right)$ can reach appreciable values. Indeed, it was found that for turnip leaves with different rates of photosynthesis in normal air and at saturating light intensities, $r_{s}$ was rather constant (about $3 \mathrm{sec} . \mathrm{cm}^{-1}$ ), but $\mathrm{r}_{\mathrm{m}}$ varied between 2 and $10 \mathrm{sec} . \mathrm{cm}^{-1}$. In most leaves of sugar beet and turnip, $r_{m}$ was between 5 and $7 \mathrm{sec} . \mathrm{cm}^{-1}$ and the minimum values of $r_{s}$ varied between 3 and $4 \mathrm{sec} . \mathrm{cm}^{-1}$ (GAASTRA, 1959).

The stomata are almost closed in darkness, and $1 / r_{s}$ increases linearly with increasing light intensity from very low values in darkness until maximum values are reached at $5-8 \times 10^{4} \mathrm{erg} \cdot \mathrm{sec}^{-1} \cdot \mathrm{cm}^{-2}$ (GaAstra, 1959; KuIPER, 1961). This range of light intensities corresponds with part of the transition range for photosynthesis (cf. FIG. 1), so that light could affect photosynthesis through an effect on both the photochemical and diffusion processes. Indeed, it was found that after a sudden increase of light intensity from limiting to saturating values, photosynthesis increased gradually and the time course corresponded with that of the opening of the stomata. In nature, this phenomenon might be of significance for leaves exposed 
to rapidly changing light intensities, which could be caused by leaf flutter, for example.

Increased $\mathrm{CO}_{2}$-concentration can induce stomatal closure, but the effect depends on light intensity. When turnip leaves were exposed to saturating light intensities, minimum values of $r_{s}$ were maintained at $\mathrm{CO}_{2}$-concentrations between 0 and $0,04 \%$. If, however, light was limiting, $r_{8}$ increased condiderably when the $\mathrm{CO}_{2}$-concentration increased from 0,01 to $0,04 \%$, but photosynthesis was not seriously affected because the effect of increased resistance was compensated by the increased $\mathrm{CO}_{2}-$ concentration, $c f$. eq. (6). Transpiration, however, decreased appreciably with increasing $\mathrm{CO}_{2}$-concentration (GAASTRA, 1959).

Another important factor influencing $r_{8}$, is the water content of the leaf. Since the water content depends on the relative rates of water supply and water loss, $r_{s}$ and photosynthesis can be influenced by all conditions which affect water uptake by the roots (e.g. root extension, soil-moisture stress, root temperature, aeration), water transport in the plant, and transpiration rate (e.g. shoot/root-ratio, absorbed radiation, temperature, wind speed, humidity of the air). Many experiments deal with the effect of soil moisture on photosynthesis (cf. SchneIder and ChILders, 1941; Loustalot, 1945; Ashton, 1956) but very little information is available on the relation between photosynthesis and absolute values of the water deficit in leaves. Perhaps, photosynthesis is increased by slight soil-moisture stress (SCHNEIDER and CHILDERS), possibly as a result of "hydro-passive" opening of the stomata (STÁLFELT, 1956). With further increasing deficiency of soil moisture, photosynthesis decreases and considerable reductions occur before wilting is visible. There is no fixed relationship between soil moisture and photosynthesis because the water deficit of the leaves depends also on the transpiration rate. In this connection it is interesting that the low photosynthetic rate of sugar cane plants growing under soil-moisture stress, increased after reduction of the light intensity (AsHTon, 1956).

Reduced water content of the leaves can reduce photosynthesis also through an effect on the mesophyll resistance. In most experiments it is not possible te separate effects on $r_{s}$ and $r_{m}$, and usually it is assumed that photosynthesis is mainly affected through changes of $r_{s}$. Scarth and SHaW (1951) and Pisek and WinkLer (1956) measured photosynthesis and stomatal opening of leaves with increasing water deficits. With equal stomatal opening but with different water deficits, photosynthesis at low deficits could be 2,5 to 3,5 times as high as at larger deficits, which suggests that photosynthesis can be reduced considerably by an increase in mesophyll resistance (cf. GAASTRA, 1962).

\section{Photosynthesis under field conditions}

Some basic properties of the photosynthetic process in leaves of crop plants were considered in the previous sections. In agriculture, however, photosynthesis per unit of soil area - i.e. the integrated effect of all leaves and other photosynthesizing tissues present per unit of soil area - is more important. In this section, some aspects of photosynthesis of crop surfaces will be briefly compared with the photosynthetic properties of leaves. More detailed treatments of the productivity of crop plants are given in several other papers presented at this Symposium.

\subsection{Light utilization by field crops}

In FIG. 5, photosynthesis per unit of soil area of an alfalfa crop, as measured by 


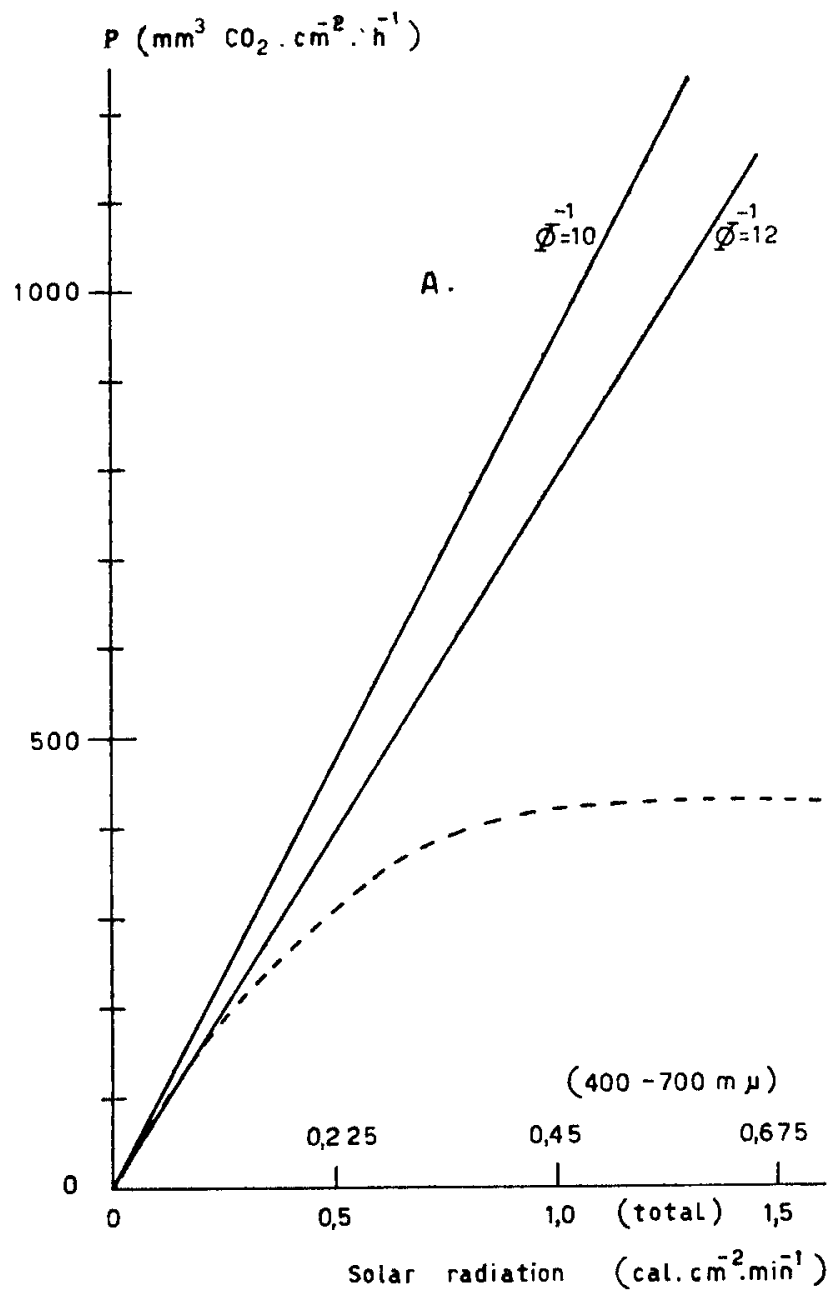

FIG. 5

Solid lines: $\mathrm{CO}_{2}$-uptake $(\mathrm{P})$ per unit of leaf area in relation to light intensity for quantum requirements $\left(\Phi^{-1}\right)$ 10 and 12.

Dotted curve: Photosynthesis (P) per unit of soil area in relation to light intensity for a field plot of alfalfa (from Thomas and HiLl, 1949)

THomas and HILL (1949), is plotted against light intensity, together with the rates of the photochemical process for quantum requirements $\Phi^{-1}=10$ and 12 . At low light intensities, the actual rate of photosynthesis is close to the optimum rate of the photochemical process, and the efficiency of light-energy conversion then is high, about $16 \%$ for solar radiation in the region between 400 and $700 \mathrm{~m} \mu$.

During the total growing period of a crop, about $1-2 \%$ of the incident solar radiation is converted into chemical energy (WAssink, 1948). Fig. 6 demonstrates that for annual crops this low efficiency is in part caused by the low leaf area per unit of soil area in the beginning of the season: The actually observed daily dry-matter production of a sugar-beet crop (GAasTRA, 1958) then is much lower than the potential daily rate of photosynthesis of a closed crop surface, calculated according to DE WIT (1959).

Much higher efficiencies, usually between 4 an $9 \%$, are observed for closed crop surfaces, cf. Nichiporovitch and ChMORA (1958), GaAstra (1958), Blackman and BLACK (1959), WASsinK (1959). These data are based upon net productions per unit 


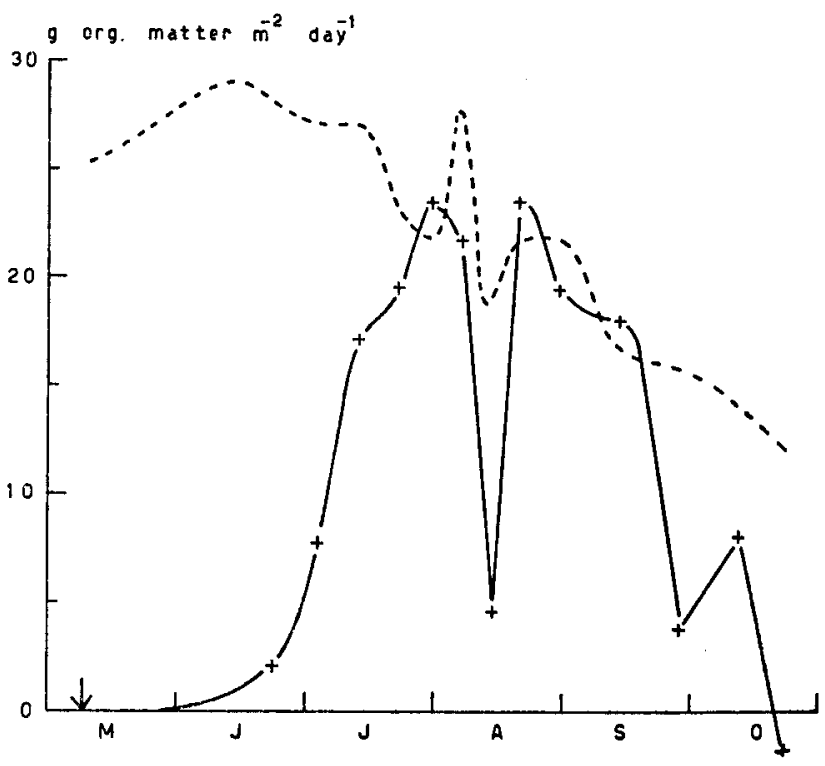

Fig. 6

Seasonal variation of daily dry-matter production by a sugar-beet crop (solid curve) and of potential photosynthesis (dotted curve) calculated according to DE WIT (1959). Sugar-beet data from GAASTRA (1958)

of soil area and per day, so that the efficiencies for gross production are about $25-60 \%$ as high. Most of these efficiencies, although much higher then those for the total growing period, are at least $50 \%$ lower then the optimum efficiency of the photochemical process. Therefore, photosynthesis of field crops must be limited markedly by the capacityy of the diffusion process. Of course, the capacities of the photochemical and diffusion process limit photosynthesis simultaneously for a large range of light intensities. As a result of mutual shading of the leaves, the transition range is much larger then for single leaves. The alfalfa crop in FIG. 5, for example, reached complete light saturation at $0,45 \mathrm{cal} . \mathrm{cm}^{-2} \cdot \mathrm{min}^{-1}$, but for most leaves this happens already at about $0,12 \mathrm{cal}^{\mathrm{cm}} \mathrm{cm}^{-2} \cdot \mathrm{min}^{-1}$.

It was shown in section 3 that the rate of the photochemical process can be affected mainly by variation of the light intensity. Photosynthesis of field crops depends, therefore, on the mode of light distribution over the leaves. Optimum light utilization occurs when the light distribution is as uniformly as possible, because the fraction of leaves exposed to light intensities beyond saturation or below compensation then is minimal. In this connection, spatial distribution of the incident light, leaf area per unit of soil area (leaf-area index), and spatial arrangement of the leaves, are important factors determining the photosynthetic rate per unit of soil area (cf. the recent review of these features by Donald, 1961).

5.2. Limitation of the photosynthetic rate of field crops by the capacity of the diffusion process

Photosynthesis of crops with optimum properties of the diffusion process can still be limited by the capacity of the diffusion process because the transition range covers a large range of light intensities and because some leaves can be exposed to saturating light intensities during part of the day.

The daily radiation wasted by leaves exposed to saturating intensities depends on leaf arrangement, leaf-area index, and on the diurnal courses of light intensity and 
solar elevation. Some idea about the fraction of daily radiation wasted in this way can be derived from DE WIT's $(1958,1959)$ calculations of the potential rate of photosynthesis of closed crop surfaces at different dates and latitudes. These calculations are based upon a somewhat simplified relationship between light intensity and photosynthesis of single leaves, and it is assumed that there is no preferred direction in the arrangement of the leaves and that the crop surface is so dense that only a negligible amount of light reaches the soil. For this model crop we calculated - using DE WIT's equations - for different daily irradiations in various months in the Netherlands, the amounts of radiation between 400 and $700 \mathrm{~m} \mu$ : incident on the crop $(\mathrm{H})$; absorbed by the crop $(0,9 \mathrm{H})$; absorbed by the crop and contributing to photosynthesis (R); absorbed by the crop and not contributing to photosynthesis $(0,9 \mathrm{H}-\mathrm{R})$, because it is in excess of the minimum amount required for complete light saturation. The amount $(0,9 \mathrm{H}-\mathrm{R})$ represents the daily radiation wasted as a result of limited capacity of the diffusion process or of sub-optimal leaf arrangement. As an example, the ratio $(0,9 \mathrm{H}-\mathrm{R}) / \mathbf{R}$ is plotted in FIG. 7 against daily radiation in June. The latter is expressed as a fraction $(H / \bar{H})$ of the average daily radiation in that month. In the same figure, the frequency distribution of $H / \bar{H}$, as given by DE VRIEs (1955) is plotted. These data suggest that photosynthesis of closed crop surfaces is limited by the capacity of the diffusion process on all days in June, with the exception of some very dull days. On an average day in June, the radiation wasted corresponds with about $40 \%$ of the radiation in the limiting and transitional range, and for about $20 \%$ of the days this fraction is $65 \%$ or more.

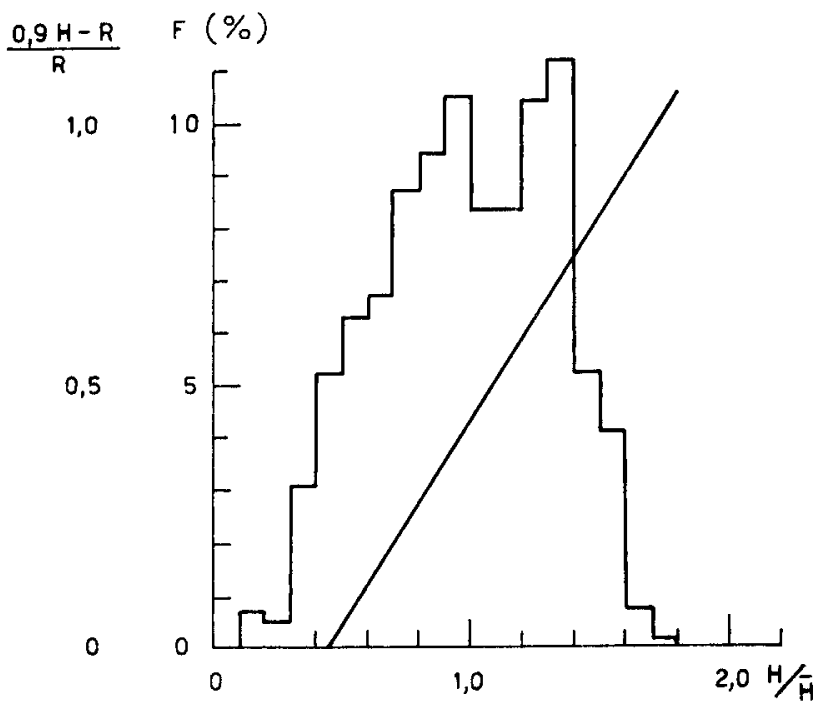

FIG. 7

Frequency distribution (F) of daily global radiation $(\mathrm{H}$, expressed as a fraction of the average value $\overline{\mathrm{H}}$ ) in June in the Netherlands (from DE VRIES, 1955)

Relation between daily global radiation $(\mathrm{H} / \overline{\mathrm{H}})$ and ratio of daily amounts of light absorbed by a crop and contributing to photosynthesis ( $R$ ) and not contributing to photosynthesis ( $0,9 \mathrm{H}-\mathrm{R})$. For explanation see text

The capacity of the diffusion process of field crops is influenced not only by the resistances described in section 4 , but also by the resistance to $\mathrm{CO}_{2}$-transport from the air above the crop towards the top of the crop $\left(r_{\text {top }}\right)$. This resistance is a function of the turbulence of the air and its relative effect on the photosynthetic rate can be estimated from the $\mathrm{CO} y$-concentrations occurring near the top of the crop ( $\left.c_{\text {top }}\right)$. If $r_{\text {atm }}$ is small as compared with the total diffusion resistance, $c_{\text {top }}$ will be about normal. However, $c_{\text {top }}$ can be as low as 0,02\% $\mathrm{CO}_{2}$ (cf. LeMON, 1960; TAMM 
and KRZYSCH, 1959, 1961), which indicates that photosynthesis of field crops can be seriously affected by variations of the turbulence of the air.

If plants are well supplied with water, the diurnal course of photosynthesis corresponds - at least qualitatively - with the diurnal course of solar irradiation (THOMAs and Hill, 1949; Moss et al., 1961). With increasing soil-moisture stress, however, the daily water loss exceeds daily water uptake, so that the water content of the leaves decreases gradually. In the beginning of the light period the water deficits are relatively small and photosynthesis then is close to normal. During the course of the day, however, deficits can increase rapidly with a consequent reduction of photosynthesis. Sometimes, deficits decrease again in the afternoon and photosynthesis can be relatively high in that period of the day (cf. Polster, 1950; AsHTON, 1956).

Photosynthesis of plants growing under soil-moisture stress could be increased if the development of critical water deficits in the leaves could be delayed until as late as possible and if photosynthesis could proceed at optimum rates during the daily period with small deficits. This could be achieved, e.g. by optimum leaf arrangement for the interception of light in the morning hours and by a high value of the ratio $r_{s} / r_{m}$ (GAASTRA, 1959). The relatively high $\mathrm{CO}_{2}$-concentrations observed in the morning hours (cf. TAMM and KRZYSCH, 1959, 1961) might be of importance through an effect on $r_{s}$. Furthermore, it would be interesting to investigate in how far genotypic differences exist with respect to the ratio value $r_{s} / r_{m}$.

\section{Conclusion}

In this paper it was tried to demonstrate that the photosynthetic rate of field crops is influenced by various physiological and structural properties of the plants as well as by various meteorological conditions. It seems, therefore, that the insight in the productivity of field crops would be promoted by a close cooperation between meteorologists and plant physiologists. Another important process in connection with the productivity of field crops is the respiration rate per plant and per day. Since this rate can be as high as $25-50 \%$ of the rate of gross photosynthesis (cf. GaASTRA, 1962), more systematic research on this subject is required.

\section{REFEREN CES}

Ashton, F. L.

BANGe, G. G. J.

Blackman, G. E., and

J. N. BLACK

Boysen Jensen, $P$.

Chapman H. W., and

W. E. Loomis

DONALD, C. M.

GaAstra, P.

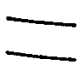

GabrieLsen, E. K.
1956

1953

1959

1932 Die Stoffproduktion der Pflanzen. Verlag G. Fischer, Jena.

1953 Plant Physiol. 28, 703.

1961 Symposia Soc. Exp. Biol. 15, 282.

1958 Meded. Landb.hogesch. Wageningen. 58 (4).

1959 Meded. Landb.hogesch. Wageningen. 59 (13).

1962 Proc. Symposium Environmental Control of Plant Growth, Canberra, 1962. (In preparation).

1947 Experientia. 3, 439.

1948 Physiol. Plantarum. 1, 5. 
HoOver, W. H.,

1933 Smithsonian Misc. Collections. 87 (16).

E. S. JoHNSTON, and

F. S. BRACKETT

KUIPER, P. J. C.

LEMON, E. R.

Loustalot, P. J.

Moss, D. N., R. B. MussGRAVE, and E. R. LEMON

Moss, R. A., and W. E. LOOMIS

Nichiporovitch, A. A., and S. N. Chmora

PISEK, A., and E. WINKLER

POLSTER $\mathrm{H}$.

RABideAu, G. S., C. S. French, and

A. S. Hol T

Scarth, G. W., and M. SHaW

SchNeIDER, G. W., and N. F. ChIL.DERS

SEYBOLD, A., and A. WeISSWEILER

STÅlfELt, M. G.

Talling, J. F.

TAMM, E., and

G. KRZYSCH

Thomas, M. D., and G. R. Hill.

VRIES, D. A. DE

WAssink, E. C.

WIT, C. T. DE

1945 J. Agr. Research. 71, 519. Bayer. Landw.schaftsverlag, München.
1961 Meded. Landb.hogesch. Wageningen. 61 (7).

1960 Agron. J. 52, 697.

1961 Crop Science. 1, 83.

1952 Plant Physiol. 27, 370.

1958 Fysiologia Rastenii. 5, 320.

Protoplasma. 46, 597.

1950 Die physiologischen Grundlagen der Stofferzeugung im Walde.

1946 Am. J. Botany. 33, 769.

1951 Plant Physiol. 26, 581.

1941 Plant Physiol. 16, 565.

1942 Botan. Arch. 43, 252.

1943 Botan. Arch. 44, 102.

1956 in Encyclopedia of Plant Physiology. III (W. Ruhland, ed.) Springer-Verlag, Berlin. p. 351.

1961 Ann. Rev. Plant Physiol. 12, 133.

1959 Z. Acker- u. Pflanzenbau. 107, 275.

1961 Z. Acker- u. Pflanzenbau. 112, 253.

1949 in Photosynthesis in Plants. (J. Franck and W. E. Loomis, eds.) Iowa State College Press, Ames, Iowa. p. 19.

1955 Meded. Landb.hogesch. Wageningen. 55, 277.

1946 Enzymologia. 12, 33.

1948 Meded. Dir. Tuinb. 11, 503.

1959 Proc. 9th Intern. Botan. Congress, Montreal, 1959.

1958 Versl. Landbouwk. Onderz. No. 64.6.

1959 Neth. J. agr. Sci. 7, 141. 